\title{
PROJETO EJA INTERVENTIVA: CONTRIBUIÇÕES PARA AS PRÁTICAS E POLÍTICAS CURRICULARES INCLUSIVAS
}

\section{PROYECTO EJA INTERVENTIVA: CONTRIBUCIONES A PRÁCTICAS Y POLÍTICAS CURRICULARES INCLUSIVAS}

\section{EJA INTERVENTIVA PROJECT: CONTRIBUTIONS TO INCLUSIVE CURRICULAR PRACTICES AND POLICIES}

\author{
Vânia de Sousa BARBOSA ${ }^{1}$ \\ Elize KELLER-FRANCO ${ }^{2}$
}

RESUMO: A EJA Interventiva é uma interface da Educação de Jovens e Adultos e Educação Especial desenvolvida no Distrito Federal para atendimento de estudantes com deficiência intelectual e autismo em defasagem idade/ano. Este artigo apresenta uma pesquisa de abordagem qualitativa na modalidade de Estudo de Caso, que objetiva analisar na perspectiva da inclusão esse projeto que se tornou Diretriz Curricular. Os resultados revelaram que a EJA Interventiva se apresenta como um projeto inclusivo bem-sucedido ao possibilitar o acesso e a permanência na educação, a continuidade da escolarização e a inserção social de estudantes com deficiência intelectual e autismo, atendendo às finalidades reparadora, equalizadora e qualificadora colocadas para a Educação de Jovens e Adultos. Evidencia-se que projetos educacionais inclusivos articulados e desenvolvidos com a comunidade escolar podem orientar atos normativos. Aponta-se que para o avanço da experiência em andamento e da educação inclusiva pesa a possibilidade substitutiva do currículo tradicional com espaços e tempos padronizados, sinalizando para a importância de se pensar propostas curriculares construídas sob novas bases, abertas à diversidade.

PALAVRAS-CHAVE: Educação de jovens e adultos. Educação especial. EJA interventiva.

RESUMEN: La EJA Interventiva es una interfaz entre la Educación para Jóvenes y Adultos y la Educación Especial desarrollada en el Distrito Federal para atender a los estudiantes con discapacidade intelectual y autismo con diferencia de edad / año. Este artículo presenta una investigación de enfoque cualitativo en la modalidad de Estudio de Caso cuyo objetivo fue analizar desde la perspectiva de la inclusión este proyecto que se convirtió en Guia Curricular. Los resultados há revelado que la EJA Interventiva se presenta como un proyecto inclusivo exitoso al posibilitar el acceso y la permanencia en la educación, la continuación de la escolaridad y la inserción social de los estudiantes con discapacidad intelectual y autismo, al servicio de los propósitos reparadores, igualadores y calificativos establecidos para la Educación de Jóvenes y Adultos. Se hace evidente que los proyectos educativos inclusivos

\footnotetext{
${ }^{1}$ Secretaria de Estado de Educação do Distrito Federal (SEEDF), Brasília - DF - Brasil. Coordenadora da EJA Interventiva no Centro de Ensino Fundamental 01 de Planaltina - DF. Mestrado em Educação (UNASP). ORCID: http://orcid.org/0000-0002-2906-9066. E-mail: v.sousa.barbosa@bol.com.br

${ }^{2}$ Centro Universitário Adventista de São Paulo (UNASP), Engenheiro Coelho - SP - Brasil. Professora permanente no Mestrado Profissional em Educação. Doutorado em Educação (PUC-SP). ORCID: http://orcid.org/0000-0003-1795-8947. E-mail: elizekeller@gmail.com
}

RIAEE - Revista Ibero-Americana de Estudos em Educação, Araraquara, v. 15, n. esp. 3, p. 2446-2470, nov., 2020. E-ISSN: 1982-5587 
articulados y desarrollados con la comunidad escolar pueden orientar los actos normativos. Se señala que para el avance de la experiencia en proceso y la educación inclusiva pesa la posibilidad sustitutiva del currículo tradicional con espacios y tiempos estandarizados, demostrando la importancia de pensar propuestas curriculares establecidas en nuevas bases, abiertas a la diversidad.

PALABRAS CLAVE: Educación de jóvenes y adultos. Educación especial. EJA interventiva.

ABSTRACT: EJA Interventiva is an interface between Youth and Adult Education and Special Education developed in the Federal District to assist students with intellectual disabilities and autism in an age-grade lag. This article presents a research of qualitative approach in the modality of Case Study that aims to analyze from the perspective of inclusion this project that became Curricular Guideline. The results revealed that EJA Interventiva presents itself as a successful inclusive project by enabling access and permanence in education, the continuation of schooling and the social insertion of students with intellectual disabilities and autism, serving the reparative, equalizing and qualifying purposes placed for Youth and Adult Education. It is evidenced that inclusive educational projects articulated and developed with the school community can guide normative acts. It is pointed out that for the advancement of the ongoing experience and inclusive education, the substitutive possibility of the traditional curriculum weighs with standardized spaces and times, signaling the importance of thinking about curricular proposals built on new bases, open to diversity.

KEYWORDS: Youth and adult education. Special education. EJA interventiva.

\section{Introdução}

A Educação é direito estabelecido para todos, cuja finalidade é o pleno desenvolvimento do educando, preparando-o para o exercício da cidadania. Apesar desta garantia, muitos estudantes experimentam dificuldades em seu processo de escolarização (físicas, intelectuais, sociais, emocionais, linguísticas ou outras), apresentando necessidades educacionais especiais para as quais as escolas devem buscar formas de educar a fim de garantir uma educação equitativa através do acesso às oportunidades educacionais de qualidade.

Em relação aos estudantes que possuem desvantagens severas, superdotados ou com necessidades educacionais especiais que se originam em função de deficiências, a Lei de Diretrizes e Bases da Educação Nacional (BRASIL, 1996) preconiza que os sistemas de ensino devem assegurar currículo, métodos, recursos e organização específicos para atender às suas necessidades.

Neste sentido, a Política Nacional de Educação Especial na Perspectiva da Educação Inclusiva (BRASIL, 2008) orienta os sistemas de ensino para garantir: acesso ao ensino regular, com aprendizagem e continuidade nos níveis de ensino; transversalidade da modalidade de

RIAEE - Revista Ibero-Americana de Estudos em Educação, Araraquara, v. 15, n. esp. 3, p. 2446-2470, nov., 2020. E-ISSN: 1982-5587 
educação especial desde a educação infantil até a educação superior; oferta do atendimento educacional especializado; formação de professores e demais profissionais; participação da família e da comunidade; acessibilidade arquitetônica; acesso à comunicação e informação.

Em consonância com as políticas voltadas para a educação inclusiva, em 2010, a Secretaria de Estado de Educação do Distrito Federal (SEEDF) apresentou ações que assegurassem aos estudantes público-alvo da Educação Especial (PAEE) que se encontravam em defasagem idade/ano, o acesso e permanência no sistema público de ensino, garantindo as condições de inclusão educacional e social por meio de sua inserção na Educação de Jovens e Adultos (EJA). Para tal, foi criado o Projeto Interventivo de Educação de Jovens e Adultos denominado de "EJA Interventiva $1^{\circ}$ segmento" voltado para o atendimento de estudantes com deficiência intelectual e autismo com ou sem associação de outras deficiências.

Em 2011, para garantir a continuidade e complementação do processo educativo dos estudantes atendidos na EJA Interventiva $1^{\circ}$ segmento, foi proposto por escolas participantes o Projeto Piloto de Educação de Jovens e Adultos Interventivo - $2^{\circ}$ Segmento. Apresentando-se como ações bem-sucedidas no atendimento a alunos com deficiência intelectual e autismo, os dois projetos levaram a SEEDF a apresentar em 2014 as Diretrizes Operacionais da Educação de Jovens e Adultos - 2014/2017, incluindo a EJA Interventiva como uma de suas modalidades, sendo referência no Distrito Federal pelo Centro de Ensino Fundamental 01 de Planaltina, estabelecimento de ensino conhecido como Centrinho, tornando-se objeto dessa pesquisa.

O critério para a escolha do contexto educacional investigado é a singularidade da experiência em andamento e as características de inovação deste programa. Além disso, estudos como os de Campos e Duarte (2011), Fantacini e Campos (2017) mostram que pesquisas sobre programas educativos que apresentem efetivas ações voltadas para a inclusão educacional e social de estudantes com deficiência intelectual e autismo no contexto da EJA ainda são escassas no Brasil, colocando a relevância e a justificativa deste estudo.

O objetivo estabelecido para esta pesquisa foi apresentar na perspectiva da inclusão o projeto para a Educação de Jovens e Adultos - EJA Interventiva $2^{\circ}$ segmento - implantado no Centro de Ensino Fundamental 01 de Planaltina/DF e analisar o impacto da modalidade para a inclusão e educação de estudantes com deficiência intelectual e autismo.

A articulação e integração da interface Educação Especial e Educação de Jovens e Adultos são os eixos norteadores desta pesquisa, que busca responder as seguintes questões: o que podemos aprender a partir da proposta da EJA interventiva em andamento no CEF 01 de Planaltina - DF para a inclusão de jovens e adultos? Quais os fatores que concorrem para o sucesso da EJA Interventiva, transformando-a de projeto piloto em política curricular? 


\section{A Educação Inclusiva: um debate importante na agenda educacional}

A inclusão é um tema que tem permeado muitos debates e discussões em nossa sociedade, principalmente na área educacional, pois se vive um momento no qual a garantia dos direitos à participação social de cada pessoa e o respeito à diversidade de gênero, étnicaracial, socioeconômica, religiosa, física ou psicológica tem emergido como uma questão ética, reivindicando uma sociedade mais justa e igualitária (PARANÁ, 2010).

Nesse contexto, amplia-se a ótica de escola inclusiva, não mais caracterizada como aquela que tem alunos com deficiência matriculados em suas turmas, mas aquela que atende a todos que apresentam necessidades referentes ao processo de aprendizagem, sendo beneficiados com recursos humanos, técnicos, tecnológicos e materiais diferenciados que promovam sua inclusão. “As escolas inclusivas são escolas para todos, implicando num sistema educacional que reconheça e atenda às diferenças individuais, respeitando as necessidades de qualquer dos alunos" (CARVALHO, 2004, p. 26).

A educação inclusiva demanda uma renovação e reestruturação da escola, o que significa fazeres diferentes para pessoas diferentes. Segundo Pacheco (2012), tratar os desiguais como se fossem iguais, em pé de igualdade, não apenas mantém a desigualdade como a aumenta. Neste sentido, Stainback e Stainback (1999), Heredero e Anache (2020) defendem que a inclusão ocorre quando as escolas são transformadas em instituições que acolhem e respondem de maneira sensível, humana e eficiente às necessidades e habilidades específicas de todos os alunos, pois todos apresentam necessidades em algum momento. Os autores acrescentam que isso demanda mais do que a inserção de alunos com deficiência em salas de ensino regular, implica a ressignificação das concepções e atitudes educacionais e a revisão dos processos de ensino.

Partindo destes pressupostos, tomamos neste estudo duas modalidades educacionais que estão voltadas ao processo de inclusão: a Educação Especial destinada aos educandos com deficiência e a Educação de Jovens e Adultos (EJA), modalidade que é a representação viva da complexidade, diversidade e pluralidade da sociedade. Nela, são atendidas pessoas jovens, adultas e idosas, sujeitos da classe trabalhadora, marcados pela diversidade de suas trajetórias pessoais ou especificidades de atendimento, que não tiveram acesso ou continuidade de estudos na idade própria. Estudantes que trazem a marca da exclusão em sua história de vida (BRASÍLIA, 2014a; BRASÍLIA, 2014b). 


\section{Procedimentos metodológicos}

Como caminho metodológico optou-se pelo estudo de caso em razão do objeto da pesquisa ter como foco um programa, um fenômeno particular, cuja descrição e compreensão proporciona novas relações, conceitos e transferência para outras situações afins (ANDRÉ, 2005).

Para a coleta de dados foram utilizados os seguintes instrumentos:

i. Análise documental, contemplando as Diretrizes Operacionais da Educação de Jovens e Adultos do DF; o Projeto Político Pedagógico do Centrinho e o Projeto Piloto de Educação de Jovens e Adultos Interventivo $-2^{\circ}$ Segmento. Constaram também avaliações diagnósticas realizadas no início das atividades dos estudantes, os Formulários de Adequação Curricular e relatórios escolares do desenvolvimento estudantil.

ii. Observação participante: uma das pesquisadoras pertence à realidade investigada. Como ambientes de observação foram privilegiadas as salas de aulas, salas de recursos, reuniões de professores, situações informais e eventos. As observações foram registradas em diário de campo.

iii. Entrevista semiestruturada: participaram das entrevistas 57 sujeitos - 33 estudantes da EJA Interventiva $-2^{\circ}$ segmento (autorizados pelos representantes legais); 05 docentes (atuantes em sala de aula e sala de recurso); 04 profissionais da equipe gestora; 02 assistentes de educação (monitor e merendeira); 02 profissionais da Secretaria de Educação/DF que participaram da construção das Diretrizes Curriculares para a EJA Interventiva 2014/2017; e, 11 pais/responsáveis de estudantes. As entrevistas foram gravadas. Antes da entrevista foi apresentado o Termo de Consentimento Livre e Esclarecido (TCLE).

A análise dos dados seguiu as fases estabelecidas por Bardin (2016): pré-análise, exploração do material e tratamento dos resultados.

$\mathrm{Na}$ pré-análise realizou-se a leitura flutuante e a escolha dos documentos. O corpus da pesquisa foi organizado por meio de um quadro que estabelecia correspondência entre os instrumentos e os objetivos da pesquisa. A seguir, os documentos coletados no estabelecimento de ensino foram organizados por temas; as observações anotadas em diário de campo foram digitadas e as gravações das entrevistas foram transcritas na íntegra.

A fase da exploração do material consistiu em realizar as operações de codificação, de classificação e de categorização, bem como, estabelecer as unidades de registro e as unidades de contexto. O tema foi escolhido como unidade de registro. Os documentos componentes do 
corpus da pesquisa foram explorados, buscando encontrar congruências e diferenças, e assim, sendo separados e organizados de acordo com temas que foram sendo estabelecidos. Após a escolha da unidade de registro, seguiu-se ao estabelecimento da unidade de contexto, que conforme Bardin (2016, p. 107), “corresponde ao segmento da mensagem, cujas dimensões (superiores às da unidade de registro) são ótimas para que se possa compreender a significação exata da unidade de registro. Isto pode, por exemplo, ser a frase para a palavra e o parágrafo para o tema”. A partir dessa organização foram estabelecidas as categorias com base no problema e objetivos da investigação em diálogo com o referencial teórico mediante a triangulação dos instrumentos utilizados, observando-se os princípios apresentados por Bardin (2016): exclusão mútua, homogeneidade, pertinência, objetividade, fidelidade e produtividade.

$\mathrm{Na}$ fase do tratamento dos resultados, os dados foram interpretados para se tornarem significativos e válidos em diálogo com o quadro teórico e os objetivos propostos para a pesquisa. Estes serão apresentados no próximo tópico. Ressalta-se que as falas dos entrevistados são apresentadas pelo sistema alfanumérico, sendo que a letra "P" designa os profissionais da escola, letra "R" pais ou responsáveis e letra "E" os estudantes.

\section{Tratamento e discussão dos dados: A EJA Interventiva - de Projeto Piloto à Diretriz Curricular}

Apresentam-se a seguir as categorias estabelecidas, a saber: I) A EJA interventiva concepção e princípios fundantes; II) A EJA Interventiva - includente/excludente; III) A EJA interventiva - suas práticas curriculares e pedagógicas; IV) O impacto da EJA Interventiva. Em face dos limites de espaço apresentaremos a análise de forma sintética, o tratamento detalhado dos dados se encontra em (BARBOSA, 2018).

\section{I) A EJA Interventiva - sua concepção e seus princípios fundantes}

Essa categoria desdobrou-se em duas subcategorias: trajetória do processo de concepção da EJA interventiva e a EJA Interventiva $2^{\circ}$ segmento e sua organização.

\section{a) A trajetória do processo de concepção da EJA Interventiva}

A EJA Interventiva é uma modalidade da Educação de Jovens e Adultos na interface com a educação especial, que integra as políticas educacionais para inclusão no Distrito Federal. Em 2009, a Diretoria de Execução de Políticas e Planos Educacionais, por intermédio da Diretoria de Educação Especial (DIEE) e a Diretoria de Educação de Jovens e Adultos (DIEJA), 
apresentou o Projeto Interventivo de Educação de Jovens e Adultos - $1^{\circ}$ Segmento, voltado para o atendimento de Estudantes com Necessidades Educacionais Especiais (deficiência intelectual e autismo) não escolarizados ou com defasagem idade/série, a ser ofertado em classes especiais, situadas nos Centros de Ensino Especial (CEE) e em instituições educacionais regulares, como é o caso do Centro de Ensino Fundamental 01 de Planaltina, lócus dessa pesquisa.

O Centro de Ensino Fundamental 01 de Planaltina, o Centrinho, iniciou suas atividades em 1972 com o atendimento à pré-escola, séries iniciais e $5^{\mathrm{a}}$ e $6^{\mathrm{a}}$ séries (atuais $6^{\circ}$ e $7^{\circ}$ anos), em 1976, passou a atender da pré-escola até a $8^{\text {a }}$ série (atual $9^{\circ}$ ano) e Supletivo das fases III e IV. $\mathrm{Na}$ sequência passa acolher estudantes com deficiência auditiva, intelectual e visual. Ao ser traçado o perfil do Centrinho que acolhe a EJA Interventiva observa-se que é uma escola voltada para a inclusão desde a sua origem. "O Centro de Ensino Fundamental 01 de Planaltina é referência em Educação Especial e Inclusiva. Além de a escola ser Polo de Deficiência Auditiva e de Deficiência Visual, ela também é Polo de EJA Interventiva" (BRASÍLIA, 2017, p. 40).

O Centrinho acolheu o Projeto EJA Interventivo $1^{\circ}$ segmento em 2010 com duas classes multisseriadas para atendimento a alunos com deficiência intelectual e autismo em defasagem idade/série e que não se adaptaram às classes regulares. $\mathrm{O}$ atendimento nesse ano foi apenas para o $1^{\mathrm{o}}$ segmento ( $1^{\mathrm{a}}$ a $4^{\mathrm{a}}$ etapas) da Educação de Jovens e Adultos, que corresponde aos Anos Iniciais do Ensino Fundamental (BRASÍLIA, 2017).

Com os avanços apresentados surgiu uma questão, o que fazer com os estudantes que estavam terminando o $1^{\mathrm{o}}$ segmento e não se adaptavam em classes comuns? A partir de acompanhamento, os profissionais do Centrinho perceberam a necessidade de construir um projeto que desse possibilidade de continuidade de escolarização para os alunos que não se adaptavam nas classes regulares e precisavam de atendimento mais individualizado. Com a experiência vivida no $1^{\mathrm{o}}$ segmento, o Centrinho construiu o projeto para o $2^{\mathrm{o}}$ segmento e apresentou à SEEDF que autorizou o funcionamento do projeto piloto no ano de 2012.

Após a implantação e avaliações do projeto piloto, foi constatada a sua viabilidade e contribuição para este atendimento educacional especializado, constituindo-se em uma nova modalidade da Educação de Jovens e Adultos do Distrito Federal, sendo incorporada às Diretrizes Operacionais da Educação de Jovens e Adultos 2014/2017 (BRASÍLIA, 2014b). 


\section{b) A EJA Interventiva e sua organização}

Conforme o Projeto Político Pedagógico do Centrinho (BRASÍLIA, 2017), constituem objetivos da EJA Interventiva $2^{\circ}$ segmento: propiciar condições de acesso e permanência com o desenvolvimento de currículo adaptado para alunos(as) da EJA com deficiência intelectual e autismo; dar continuidade à EJA Interventiva $1^{\circ}$ Segmento e acolher os indivíduos que estão fora da escola ou em inclusão em classes regulares e que não se adaptaram a essas; promover condições de formação do(da) estudante de forma a melhorar seu nível de escolarização e viabilizar melhores condições de capacitação para desempenho de atividades profisssionais; possibilitar a sensibilização e a formação continuada dos(das) profissionais de educação.

A EJA Interventiva é organizada em regime semestral, por segmentos e etapas que guardam uma correspondência com a organização da Educação Básica. O $2^{\circ}$ segmento da EJA ( $5^{\mathrm{a}}$ a $8^{\mathrm{a}}$ etapas) corresponde aos Anos Finais do Ensino Fundamental (BRASÍLIA, 2014a).

O estudante pode desenvolver o currículo do $2^{\circ}$ segmento da EJA num prazo de até 08 (oito) semestres, 2 (dois) semestres para cada uma das quatro etapas, ao passo que na EJA tradicional o estudante tem um semestre para concluir cada etapa. Isso acontece devido à necessidade de "flexibilização curricular na temporalidade voltada a respeitar o ritmo e o desempenho individual desse estudante" (BRASÍLIA, 2011, p. 10).

O projeto prevê, além das 400 horas/aula semestrais de atividades pedagógicas do currículo de EJA, 200 (duzentas) horas/aula semestrais de atividades pedagógicas na área de Educação Profissional, em caráter de complementação. Nestas atividades são desenvolvidos conteúdos sobre Habilidades Básicas, Gestão para o Trabalho e atendimento do Serviço de Orientação para o Trabalho (SOT), duas vezes por semana, no contraturno.

A avaliação é realizada de forma processual ao longo do semestre. Ao final deste, o Conselho de Classe formado pelos professores regentes, da sala de recursos e equipe pedagógica analisam se o aluno atingiu os objetivos observando as adequações curriculares propostas. Quando os objetivos não foram alcançados, mas ocorreu a aprendizagem no ritmo do estudante, é concedida a temporalidade com direito a mais um semestre na etapa. É previsto também a progressão continuada que pode ocorrer a qualquer tempo do percurso educativo, bem como, o encaminhamento para a classe regular inclusiva a qualquer momento.

Quando o estudante esgota o tempo previsto para sua permanência no projeto e é evidenciado que não atinge o nível pedagógico esperado para as etapas, é concedida a terminalidade do Ensino Fundamental e o estudante é encaminhado para participação em programas sócio profissionalizantes (BRASÍLIA, 2011).

RIAEE - Revista Ibero-Americana de Estudos em Educação, Araraquara, v. 15, n. esp. 3, p. 2446-2470, nov., 2020. E-ISSN: 1982-5587 
A análise da concepção e dos princípios fundantes da EJA Interventiva $2^{\circ}$ segmento, revela que essa se estabeleceu a partir da comunidade escolar, das práticas desenvolvidas pelos profissionais da escola, das especificidades dos estudantes e das necessidades que surgiram no contexto escolar em diálogo com a Secretaria de Estado de Educação. Uma política curricular que se originou de dimensões articuladoras que compreendem as instituições educacionais enquanto espaços corresponsáveis, na qual a criação de um projeto piloto educacional induziu à criação das Diretrizes Curriculares para a EJA Interventiva no Distrito Federal.

A Gênese da EJA Interventiva se situa na direção apontada por Heredero e Anache (2020, p.), de que “o processo inclusivo é uma construção coletiva, que necessita do envolvimento de toda a comunidade que circunscreve a escola: alunos, professores, gestores, demais funcionários, famílias, poder público e sociedade".

\section{A Percepção dos Participantes quanto à EJA Interventiva: includente ou excludente?}

Com a finalidade de analisar a percepção dos participantes da pesquisa quanto à EJA interventiva numa perspectiva de inclusão, solicitou-se a esses que avaliassem a proposta como um processo includente ou excludente. Das respostas emergiram as seguintes subcategorias:

\section{a) Possibilita o acesso à Educação e continuidade de estudos}

De acordo com a fala dos entrevistados, a EJA Interventiva tem se apresentado como importante alternativa de continuidade de estudos e para a aquisição de conhecimentos para estudantes jovens e adultos com deficiência intelectual e autismo que estavam fora do processo de escolarização formal ou em situações de exclusão em salas do ensino regular.

F2: A EJA Interventiva eu considero como inclusão, porque nós temos vários alunos que já estavam em casa, né?! Que os professores consideraram que não aprendiam mais e eles avançaram. Dando condições, eles avançaram.

R3: Ah! É uma coisa muito boa, né?! Ainda mais pra eles que não podem estudar à noite, pra eles aqui é bem melhor! Porque senão... no caso dela, ela não ia nem estudar. Porque só tem no [...] e à noite né?!

Através do Formulário de Movimento e Rendimento Escolar (2010-2017) verificou-se que o número de matrículas dos estudantes na EJA Interventiva cresceu significativamente entre 2010 e 2017, passando de 13 estudantes matriculados em 2010 para 86 em 2017, possibilitando o acesso à educação e a continuidade de estudos.

RIAEE - Revista Ibero-Americana de Estudos em Educação, Araraquara, v. 15, n. esp. 3, p. 2446-2470, nov., 2020. E-ISSN: 1982-5587 


\section{b) Promove a articulação com o Ensino Regular}

A EJA Interventiva está inserida em uma escola de Ensino Regular, proporcionando a socialização com estudantes sem deficiência e ao mesmo tempo oportunizando o atendimento educacional especializado.

F5: O momento em que eles têm destinado para o estudo, para aquisição de novos conhecimentos do conteúdo formal, eles estão num ambiente mais restrito, que é organizado pra atender a necessidade especifica deles de aprender. Porém, fora esse momento, eles participam de todas as atividades na escola.

Conforme descrito no Projeto Político Pedagógico do Centrinho (BRASÍLIA, 2017), os estudantes da EJA Interventiva participam de todas as atividades propostas pela escola (passeios pedagógicos, campeonatos esportivos, apresentações, festas, festivais etc.). Um ambiente inclusivo, favorecedor da socialização, também pode ser percebido nas falas dos estudantes.

E4: Tem intervalo. Todo mundo conversa com tu. Lá na outra escola ninguém conversava comigo no intervalo. Todo mundo falava mal de mim. Que eu era esquisita (risos). Nem os professores falavam comigo direito. Aqui é diferente. Eu tenho amigos.

E5: É igual eu falei, os colegas, as amizades... lá eu tinha pouco. E aqui não. Aqui eu vou pra cima e pra baixo e os meninos conversam comigo, é eu dizendo as coisas pros meninos... Eu me alegrando... eu não tinha alegria no colégio.

Ações voltadas à efetivação da inclusão educacional e social aos estudantes da EJA interventiva foram presenciadas pela pesquisadora por meio da observação participante, (Diário de Campo, ag/2017), incluindo a realização de dias letivos temáticos com o envolvimento de toda a escola, projetos nos quais todos os estudantes participam e atividades do cotidiano escolar como a participação no horário do intervalo e do lanche.

Este ambiente inclusivo proporcionado pela EJA Interventiva, uma classe de atendimento especializado em uma unidade escolar de classes regulares, na qual os alunos participam de atividades que integram toda a escola, mostra-se favorável para o desenvolvimento dos conhecimentos curriculares e para a socialização destes estudantes. 


\section{c) Desenvolve a aprendizagem do estudante}

A EJA Interventiva possibilita o acesso dos estudantes tanto ao currículo funcional quanto ao currículo comum da Educação Básica, proporcionando o desenvolvimento de suas aprendizagens através de práticas curriculares e pedagógicas que atendam às suas necessidades.

F1: Então eu acho que aqui na EJA Interventiva é uma oportunidade, porque lá [...] é só o currículo funcional. [...] Então eu acho que a EJA Interventiva é uma oportunidade sim, que dá valor ao cognitivo, à aprendizagem, ao conteúdo. Porque querendo ou não a gente tem toda uma forma de lidar e tem a afetividade que é muito importante aqui na escola. Mas, falando do valor que a nossa sociedade dá à escrita e aos números, é uma oportunidade de aprenderem isso, porque eles têm mais dificuldade que os nossos alunos do regular. A gente sabe que o tempo deles é bem diferente dos outros alunos.

F8: A EJA Interventiva resgatou esses alunos, trouxe pra escola, trouxe pra interação, trouxe para o desenvolvimento cognitivo, para a aprendizagem, né?!

R1: É inclusão mesmo, né?! Põe o aluno lá, mas dá assistência! Dá atenção, trabalha com ele direitinho. [...] Aqui ele está aprendendo.

O acesso do estudante da EJA Interventiva aos conteúdos formais do currículo consta das finalidades declaradas no PPP do Centrinho (BRASÍLIA, 2017), justificando que a falta de uma formação básica é um entrave para inserção no mundo do trabalho e inserção na sociedade. O acesso ao currículo funcional também é necessário nesse processo, pois envolve atividades de desenvolvimento de habilidades da vida diária como: consciência de si, cuidados pessoais, treinamento multissensorial, exercício da independência, relacionamento interpessoal, possibilitando ao estudante a prática de situações cotidianas com autonomia.

Os dados do Formulário de Movimento e Rendimento Escolar (2010-2017) da EJA Interventiva do Centrinho e Estudos de Caso dos estudantes demonstram que nos oito anos de funcionamento o número de alunos que conseguiram desenvolver a aprendizagem é bastante significativo, com destaque para os anos de 2012 e 2015 nos quais $100 \%$ dos alunos foram considerados aptos para avançarem de etapa e segmento.

\section{d) Possibilita a profissionalização do estudante com deficiência e o encaminhamento para o mundo do trabalho}

Segundo o Projeto Político Pedagógico (BRASÍLIA, 2017), além do foco em ações pedagógicas que atendam às necessidades educacionais especiais do alunado, a EJA Interventiva propicia condições para a inserção desse aluno no mundo do trabalho. Para isso, desenvolve ações integradas com Serviço de Orientação para o Trabalho - SOT e escolas

RIAEE - Revista Ibero-Americana de Estudos em Educação, Araraquara, v. 15, n. esp. 3, p. 2446-2470, nov., 2020. E-ISSN: 1982-5587 
técnicas, bem como, oferece cursos pelo Pronatec/MEC. Como resultado dessas parcerias, empresas têm procurado tanto o Centrinho quanto o SOT do CEE no sentido de contratar estudantes. De acordo com o PPP do Centrinho, “entre 2010 e 2016, diversos estudantes foram encaminhados (as) para o mercado de trabalho" (BRASÍLIA, 2017, p. 42). Em 2017, durante a pesquisa, três estudantes já haviam sido encaminhados e estavam trabalhando.

Nota-se que a EJA Interventiva, além de garantir o acesso à Educação e compensar situações de fracasso escolar, tem proporcionado o atendimento e a inserção do estudante como cidadãos(ãs) de direito mediante qualificação para o mundo do trabalho.

\section{e) Proporciona o desenvolvimento da independência e autonomia nas habilidades da vida}

\section{diária do estudante}

Outro aspecto que contribui para a percepção da EJA Interventiva como includente é o trabalho realizado com os estudantes que chegam à escola dependentes nas habilidades da vida diária.

F8: A escola e a sala de recursos chamam as famílias para reuniões $e$ explicam situações da vida desses alunos e falam da necessidade de proporcionar uma independência pra eles. E uma outra coisa que eu acho legal também é que aqui a gente tenta passar pra eles esses valores da independência. Então, por exemplo, "Vamos lanchar". "Ah! Eu vou lá buscar o lanche porque esse aluno é especial e vou entregar na mãozinha dele”. Não. Eles vão lá buscar o seu próprio lanche. Derramou suco na sala de aula, por exemplo, ele vem aqui buscar o pano. Ele vem aqui chamar a moça da limpeza. Não precisa ninguém vir fazer por eles, né?! Então, essa questão da independência também é bem forte na EJA Interventiva.

Conforme relatos, uma prática importante é fazer a ligação do que o aluno vai aprender em sala de aula com as atividades do seu dia a dia:

F8: A proposta pedagógica que faz a diferença é a amarração do que é aprendido na escola e a vida prática dele. O que ele aprende aqui que pode ser utilizado na vida prática? A gente tenta é... fazer o básico funcionar. Por exemplo: como pegar um onibus? É preciso saber ler a placa do ônibus. Pra ir pro mercado, precisa além de ler a embalagem do produto, saber lidar com dinheiro. Vai dar um valor, eles irão dar um troco, é preciso conferir esse troco. Então são noções pra vida prática dele. É essa amarração do que é ensinado, o conteúdo que é ensinado aqui em relação à vida do aluno fora daqui.

F5: E esses assuntos assim relacionados a habilidades básicas, né?! Para o convívio social e habilidades básicas de gestão da própria vida, né?! Se entender como alguém que participa de um grupo, que é capaz de interagir naquele grupo, de transformar aquele grupo. Então como pessoa cidadã que necessita ter as suas opiniões e de interagir com os demais, de transformar as suas realidades, de saber que eles têm direitos, mas têm obrigações, que

RIAEE - Revista Ibero-Americana de Estudos em Educação, Araraquara, v. 15, n. esp. 3, p. 2446-2470, nov., 2020. E-ISSN: 1982-5587 
existe um... um comportamento social que eles precisam entender e se adequar ao ambiente de trabalho, ao ambiente domiciliar, aos locais de socialização, né?! Então, assim, é um conteúdo organizado pra vida deles. A gente se preocupa muito com a independência deles.

Como resultado deste trabalho, estudantes que ingressaram na escola dependentes têm avançado pedagogicamente, socialmente, financeiramente e nas habilidades da vida diária:

F2: Aí, aluno que o pai não deixava isso, não deixava aquilo, porque a escola, porque o laudo... E que hoje vem sozinho de ônibus, né?! Então, isso é inclusão. Apesar dele estar dentro de uma sala com os pares dele que também são DI, que a princípio parece que seja exclusão, ele avançou financeiramente porque já trabalha; pedagogicamente, porque aprendeu, né?! Ele avançou socialmente, porque namora, né?! E então, não é inclusão isso aqui?

\section{f) Desenvolve a autoestima dos estudantes}

Dentre as ações citadas pelos respondentes como característica includente da EJA Interventiva está o resgate da autoestima. Conforme Traversini (2009), a autoestima é um dos objetivos a serem atingidos em propostas de políticas educacionais inclusivas. "O sentimento de opressão e de inferioridade, a vergonha, o estigma por não saber ler e escrever e o temor do preconceito são condições geradoras de baixa autoestima” (TRAVERSINI, 2009, p. 583).

A garantia do retorno à escola, bem como o desenvolvimento da aprendizagem no alunado atendido pela EJA Interventiva, tem proporcionado o aumento da autoestima destes.

F1: Eu acho que mexe com a autoestima, porque aqui na EJA Interventiva ele pode ser aprovado, ele aprende ainda que a adequação dele seja enorme, né?! Ainda que precise de uma temporalidade, mas ele aprende. [...] $\mathrm{O}$ que eles apresentam é uma autoestima elevadíssima.

Observa-se que a EJA Interventiva mediante o acesso à educação tem oportunizado ao estudante o exercício pleno da sua cidadania e o desenvolvimento de sua autoestima.

\section{g) Promove o respeito à diversidade}

A análise do PPP revela um conjunto de projetos voltados para a temática da diversidade, como por exemplo "Projeto Cine Diversidade", "Projeto Sexualidade", "Rádio Diversidade", "Projeto Quem Somos Nós" e "Projeto Diversidade na Escola". Este último foi premiado nacionalmente por duas vezes e indicado para uma premiação internacional. Conforme o PPP, esses projetos têm como objetivo "promover a cidadania plena no ambiente

RIAEE - Revista Ibero-Americana de Estudos em Educação, Araraquara, v. 15, n. esp. 3, p. 2446-2470, nov., 2020. E-ISSN: 1982-5587 
escolar, onde as pessoas possam se reconhecer do ponto de vista da equidade, tendo suas diferenças respeitadas" (BRASÍLIA, 2017, p. 101).

Estudos demonstram que quando há atividades organizadas no processo ensinoaprendizagem que respeitam os ritmos de aprendizagem através da oferta de métodos e currículos que atendam às necessidades específicas de cada estudante e que promovam demonstrações de afetividade, os alunos se sentem acolhidos, respeitados em suas diferenças e pertencentes ao grupo (LAFFIN, 2007; FANTACINI; CAMPOS, 2017).

$\mathrm{Na}$ fala dos funcionários transparece uma postura de respeito à diversidade. Percebem a inclusão como um processo no qual o sujeito se sente igual, mas não no sentido de anular as suas diferenças e sim no sentido de ser tratado com equidade, de ter as suas especificidades respeitadas.

F1: É colocar alguém em uma situação que se sinta igual. Igual não é anular as diferenças. [...] Eu acho que quando você é incluido, e isso é quando você se sente bom praquele lugar. É você perceber todas as diferenças, trabalhálas, dar chances e oportunidades.

F6: Eu acho que a inclusão é a capacidade da escola de receber os alunos com aprendizagens diferentes, forma de aprender diferente, de formas sociais diferentes... Eu acho assim, é conseguir receber esses alunos todos. Fazer com que esses alunos se sintam parte da escola.

A análise documental e as entrevistas permitem vislumbrar ações e percepções que consideram a normalidade na diferença, partindo do pressuposto de que a inclusão tem como finalidade a valorização e o respeito à diversidade.

Esta síntese das subcategorias que emergiram das entrevistas, da análise documental e da observação, apontam para a EJA Interventiva como includente. Entretanto, uma representatividade de $37 \%$ dos pais/responsáveis não se posicionou sobre a EJA Interventiva como includente ou excludente, declarando a falta de conhecimento sobre o que é o processo de inclusão.

Um pai/responsável e um funcionário posicionaram-se como um processo intermediário: em determinado momento é includente (quando estão envolvidos nas atividades juntamente com os estudantes matriculados nas classes regulares) e em outro é excludente (quando estão separados na hora do contato e da aprendizagem dos conteúdos curriculares).

A análise demonstra que a polarização que tem estado no cerne da questão da inclusão ainda se apresenta como um campo de forças e embates, que com relativa frequência tem se reduzido à discussão da tendência hegemônica de embasar a inclusão de estudantes com deficiência como sua inserção nas classes regulares de ensino.

RIAEE - Revista Ibero-Americana de Estudos em Educação, Araraquara, v. 15, n. esp. 3, p. 2446-2470, nov., 2020. E-ISSN: 1982-5587 
Documento intitulado "Inclusão e Diversidade: Reflexões para a Construção do Projeto Político-Pedagógico" (PARANÁ, 2010), considera três tendências sobre o modo de pensar e praticar a inclusão: a) A Inclusão Condicional - o seu funcionamento depende de situações como o professor estar capacitado para o atendimento, as escolas estarem adaptadas, a diminuição do número de alunos por turmas, a presença de um especialista como auxiliar; b) A Inclusão Total ou Radical - inclui todos os alunos no Ensino Regular de forma irrestrita; c) A Inclusão Responsável - repensa e reestrutura políticas e práticas pedagógicas de forma a criar oportunidades de acesso à escola, continuidade nos estudos e garantir condições de aprendizagem para os estudantes PAEE.

A análise dos dados revelou que a EJA Interventiva segue a linha da Inclusão Responsável e se mostra como um fator positivo no processo de formação e escolarização de jovens e adultos com deficiência intelectual e autismo.

\section{A EJA Interventiva e suas Práticas no Processo de Formação dos Estudantes}

Uma educação inclusiva demanda mudanças profundas nos sistemas de ensino com o objetivo de proporcionar uma educação elevada a todos os alunos. Pois, "inclusão não significa, simplesmente, matricular os alunos com necessidades especiais na classe comum, ignorando suas necessidades específicas, mas significa dar ao professor e à escola o suporte necessário à sua ação pedagógica" (FRIAS; MENEZES, 2009, p. 29).

Buscando conhecer as práticas realizadas no processo de formação dos estudantes atendidos pela EJA Interventiva no Centrinho e que a tornaram um projeto bem sucedido induzindo à criação de diretrizes, emergiram duas subcategorias: as práticas curriculares e as práticas pedagógicas na EJA Interventiva.

\section{a) As práticas curriculares na EJA Interventiva}

As Diretrizes Operacionais da Educação de Jovens e Adultos estabelece que o currículo da EJA Interventiva deve ser "adequado e adaptado com metodologias e técnicas específicas, conforme as necessidades dos estudantes. Deverá ocorrer ainda, a flexibilização na temporalidade do $1^{\circ}$ e $2^{\circ}$ segmentos considerando o desempenho desse estudante" (BRASíLIA, 2014b, p. 46).

As adaptações/adequações curriculares constituem-se de alterações compatíveis com as necessidades dos estudantes: 
Realizar adequações curriculares implica, portanto, numa postura de disponibilidade dos agentes educacionais em atuar de forma diversificada e eficaz frente às dificuldades de aprendizagem dos estudantes. Essa atuação manifesta-se em níveis e formas diversas, por isso serão observadas desde pequenas e diárias adequações a grandes e mais profundas reorganizações no currículo. Esta última situação, em muitos casos, acarretará inclusive a busca de recursos especiais para uma solução adaptada a cada caso. Portanto, mostra-se imprescindível para o sucesso do processo de aprendizagem dos estudantes que necessitam de respostas educacionais adequadas, que se realizem graduais e progressivas adaptações do currículo, para torná-lo apropriado às peculiaridades dos estudantes com necessidades especiais (BRASÍLIA, 2010, p. 40).

Ao direcionar a análise para os sujeitos envolvidos, em especial aos professores, aparece menção à utilização do currículo adaptado:

F6: A ideia da inclusão, ela já fala da questão do currículo adaptado. O professor é responsável pra adaptar a atividade, adaptar o curriculo, adaptar a prova. Faz parte acho que da atribuição do professor que quer trabalhar com Ensino Especial, né?! E, é dificil. É preciso de tempo. Precisa parar e pensar qual vai ser a melhor atividade para aquele aluno.

A análise documental demonstrou que o PPP do Centrinho (BRASÍLIA, 2017), bem como o Projeto Piloto da EJA Interventiva - $2^{\circ}$ segmento (BRASÍLIA, 2011), apresentam como objetivo desta modalidade proporcionar a implementação do currículo adaptado. No entanto, a análise das adaptações e adequações realizadas na EJA interventiva comparada ao currículo proposto para a EJA sugere que há um enxugamento dos conteúdos e não necessariamente uma organização significativa pensada para a realidade destes alunos. Indícios de enxugamento observado na análise documental, aparece na entrevista:

F9: Não é uma diferença gritante. A gente vê assim, a gente usa a adequação, usa esses termos, dando bem assim uma enxugada...

A Instituição dispõe também do Formulário de Registros das Adequações Curriculares. A análise permitiu verificar que o formulário é preenchido de forma geral para todos os estudantes, sendo uma adequação para a sala de aula e não adaptações individuais. Este fato encontra reforço na fala da profissional:

F3: Mas no geral a adequação é coletiva. A única parte que é individual é aquele primeiro momento que a sala de recurso faz, que é a idade que o aluno entrou na rede, quais escolas que ele passou, com quantos anos ele foi alfabetizado, a deficiência... Essa parte é individual, mas a parte que tem de conteúdo, de acessibilidade e organização da sala de aula, é tudo copia e cola, tudo copia e cola. 
Observa-se ainda que mesmo havendo a orientação de que as adequações devam ser organizadas e preenchidas em conjunto pelos professores regentes e profissionais da sala de recurso, conforme estabelecido no Projeto Piloto (BRASÍLIA, 2011), há indícios de que a elaboração coletiva não está sendo efetiva, conforme revela a fala:

F3: Nem leem direito a adequação curricular que a gente faz. Chega lá, copia, cola o conteúdo e assina. Então eles não têm essa... Poucos... não digo todos, tem as suas exceções [...]. Ai veio essa professora, que é um contrato temporário. No início assim a gente fez... eu fiz com ela num primeiro momento, mas assim... nunca mais ela voltou... porque eu pedi pra que ela me atualizasse com os conteúdos que ela estivesse trabalhando em sala, pra eu poder preparar minhas aulas no atendimento. Nunca mais voltou.

A flexibilização na temporalidade é outro aspecto contemplado no currículo da EJA Interventiva. "As adequações na temporalidade referem-se à flexibilização do tempo previsto para a conclusão de determinados conteúdos, objetivos ou unidades curriculares" (BRASÍLIA, 2010, p. 47). A análise da flexibilização da temporalidade nos formulários das adequações dos estudantes demonstrou que $96 \%$ dos estudantes necessitam do aumento do tempo previsto para alcançar os objetivos propostos pelo currículo.

$\mathrm{O}$ currículo da EJA Interventiva $2^{\circ}$ segmento contempla ainda o Atendimento Educacional Especializado (AEE), uma atividade pedagógica realizada nas salas de recursos por professores especializados cujas funções são identificar, elaborar e organizar "recursos pedagógicos e de acessibilidade que eliminem as barreiras para a plena participação dos alunos, considerando suas necessidades específicas" (BRASIL, 2008, p. 16).

Cada turma tem seu horário para atendimento na sala de recurso. Dependendo da atividade, o atendimento é realizado para toda a turma, em grupos, em duplas ou individualmente. São oferecidas atividades diversificadas com recursos lúdicos, jogos didáticos e dinâmicas que buscam desenvolver o cognitivo, o motor, o socioafetivo, o emocional, a aprendizagem do estudante em todos os sentidos. Os estudantes são auxiliados nas atividades de sala de aula e recebem reforço nos conteúdos (Diário de Campo, ag/2017).

Da análise sobre as práticas curriculares, depreende-se que a EJA Interventiva vem desenvolvendo esforços na direção de pensar um currículo para atender a necessidade de seus alunos, tais como as adaptações/adequações curriculares, a flexibilização na temporalidade e o atendimento educacional especializado, no entanto há indicadores que ainda é preciso solidificar algumas iniciativas.

A partir dos formulários de adequações e relatórios estudantis foi possível observar que as adaptações curriculares têm ficado restritas à dinâmica geral da sala de aula, não foram 
observadas adequações individuais. A análise levantou ainda o alerta para que as adaptações não sejam vistas como enxugamento do currículo.

A análise das práticas curriculares da EJA interventiva revela que esta busca atender as proposições do marco legislatório educacional brasileiro para atendimento dos educandos com necessidades especiais mediante critérios de adaptação/adequação e flexibilização curricular, mas levanta a problematização sobre o currículo para uma escola inclusiva: seria uma questão de adaptação curricular ou envolve uma revisão dos currículos em sua totalidade?

\section{b) As práticas pedagógicas na EJA Interventiva}

Diante da diversidade de especificidades apresentadas pelos estudantes com deficiência e do direito ao desenvolvimento de sua aprendizagem, o processo inclusivo pressupõe também mudanças na organização dos espaços, práticas pedagógicas, metodologias e avaliação (FRIAS; MENEZES, 2009).

No Centrinho, a organização do ambiente escolar tem se demonstrado efetivo, tanto na acessibilidade física, como nas práticas pedagógicas. $\mathrm{O}$ atendimento às especificidades dos estudantes com Deficiência Intelectual e Transtorno do Espectro Autista atendidos pela EJA Interventiva exige um ambiente com menos barulho, com menos movimentação, que facilite o contato individualizado do professor com o educando no momento da realização de atividades.

Além de contar com um ambiente específico para o momento da aprendizagem, o espaço em sala de aula adquire diferentes formatos de organização, de acordo com as atividades e necessidades. A observação revelou atividades em mesas agrupadas quando se propunha produções, conversas e discussões em pequenos grupos. Rodas de conversa quando se queria estimular o diálogo e a socialização. A organização da sala em duplas para proporcionar oportunidades de ajuda mútua. Atividades individuais para desenvolver as habilidades e competências dos estudantes com autonomia e independência. Além das diversas organizações do espaço da sala de aula, todo o espaço da escola é utilizado para o desenvolvimento de atividades propostas, como o projeto de leitura ao ar livre (Diário de Campo, ag/2017).

Materiais e metodologias diversificadas e adaptadas são utilizados dentre as práticas pedagógicas da EJA Interventiva:

F8: [...] tem que trabalhar o lúdico, adaptação da linguagem, o carinho, o acolhimento [...] E, também a capacidade mesmo de trabalhar com o concreto, material concreto.

F8: [...]. Eu acho que o profissional da Educação, seja ele na EJA Interventiva ou não, ele tem que sempre se atualizar. Mas eu acho que com a EJA, ainda mais, porque a metodologia de ensino tem que estar preparada

RIAEE - Revista Ibero-Americana de Estudos em Educação, Araraquara, v. 15, n. esp. 3, p. 2446-2470, nov., 2020. E-ISSN: 1982-5587 
para aqueles alunos, [...] eu acho que a linguagem é importante. A linguagem pra trabalhar com a EJA, ela tem que ser adaptada, ela tem que ser simplificada, ela tem que ser lúdica, ela tem que ser exemplificada, né?! Hoje mesmo a menina perguntou se a gente trabalhava questões étnico-raciais e de gênero com os alunos da EJA Interventiva. Eu disse que sim. Ela: "Como?". Ai eu falei, "Por exemplo, por meio de peças teatrais". Aquela peça do Flicks, né?! [...] É uma caixa de lápis de cor [...] e uma cor se achava excluída, porque era diferente. Então, essa peça é uma metáfora do que a gente via aqui, né?! De que não pode haver exclusão, todos são iguais, todos têm que ser respeitados. Teve outra também, que era o reino animal, né?! Que alguns animais eram desprezados, por serem diferentes. Essa temática era trabalhada dessa forma, né?!

O PROINESP é um laboratório de informática organizado para dar suporte aos professores na elaboração de materiais e para proporcionar acesso à informatização aos estudantes. São computadores adaptados às várias necessidades e diversos instrumentos metodológicos disponibilizados, tais como jogos educativos, softwares educacionais, dentre outros (BRASÍLIA, 2017).

As saídas de campo também são meios utilizados para que os estudantes se apropriem do mundo vivo com o intuito de fazer uma ligação com os conhecimentos adquiridos em sala de aula e para proporcionar momentos de inclusão com os alunos do Ensino Regular:

F9: É, a escola faz sempre saidas de campo interessantes com eles. Não é aquela saída, ah! só pra dizer que saiu da escola, não. [...] Só passeio. Sempre tem ali algo que pode ser trabalhado com eles.

F3: Então, o que tem que ser para o regular tem que ser para o EJA. Se tem um passeio para o clube, é para o EJA e para o regular. Se tem uma visita pedagógica no Instituto Histórico e Geográfico, para o EJA e para o Ensino Regular. A gente tem que... eu acho que a gente tem que proporcionar momentos dessa inclusão do EJA com o Ensino Regular.

O trabalho com projetos consta como uma das práticas pedagógicas no PPP do Centrinho, definido como "uma metodologia que favorece a aquisição do conhecimento, ressignificando o processo de ensino e de aprendizagem" (BRASÍLIA, 2017, p. 100). No entanto, observou-se que a riqueza dos projetos verificada na análise do PPP do Centrinho (BRASÍLIA, 2017) manifestou-se com baixa intensidade na fala dos docentes.

Os instrumentos utilizados nessa pesquisa que deram acesso à análise dos materiais e metodologias em uso na EJA do Centrinho demonstraram que há uma diversificação de materiais e metodologias, no entanto, com base nas respostas dos entrevistados que se manifestaram de forma genérica, defende-se que esse é um ponto que pode avançar. 


\section{O Impacto da EJA Interventiva}

Os dados coletados apresentaram indicadores do impacto positivo da EJA interventiva para a inclusão de estudantes jovens e adultos com deficiência, bem como sua importância para a indução de políticas curriculares para essa modalidade, orientando o estabelecimento das seguintes subcategorias: função reparadora da EJA interventiva, função equalizadora da EJA interventiva e função qualificadora da EJA interventiva.

\section{a) A função reparadora da EJA Interventiva}

A função reparadora atende a inúmeros estudantes que em sua trajetória educacional não tiveram o atendimento correlato idade/ano escolar e nem a garantia da continuidade de seu processo de escolarização. Desta forma, verifica-se que, ao trazer os alunos de volta ao processo de escolarização, a EJA Interventiva cumpre com sua função reparadora.

Ao analisar a procedência dos estudantes da EJA interventiva observa-se que são indivíduos que estavam fora do processo de escolarização e haviam recebido a certificação de terminalidade; ou que haviam parado de estudar devido a problemas pessoais ou por não apresentarem o desenvolvimento da aprendizagem; ou ainda que participavam de oficinas sociopedagógicas sem estar inseridos num processo de escolarização; ou estavam em classes comuns inclusivas, porém em defasagem de idade/ano e de aquisição de conhecimentos curriculares propostos para o ano escolar.

A própria origem da EJA Interventiva do Centrinho é uma exemplificação da função reparadora, pois surgiu da necessidade de acolher estudantes que estavam fora do processo de escolarização, possibilitando o acesso, o retorno e a continuidade da vida escolar.

\section{b) A função equalizadora da EJA Interventiva}

A função equalizadora da EJA Interventiva busca restabelecer a trajetória escolar dos jovens e adultos com deficiência atendidos, pois possibilita ao estudante "retomar seu potencial, desenvolver suas habilidades, confirmar competências adquiridas na educação extraescolar e na própria vida, possibilitar um nível técnico e profissional mais qualificado" (BRASIL, 2000, p. 10).

Ao serem indagados sobre a importância da EJA Interventiva, estudantes e responsáveis declararam que sua relevância está em proporcionar o desenvolvimento das potencialidades estudantis e da aprendizagem dos conteúdos curriculares e habilidades básicas para a vida. 
R4: Ah! aqui é muito bom. [...] aqui ele aprendeu a ler, assim... ele conversa mais. Ele era fechado, agora ele se expressa mais. Nossa! Com a gente dentro de casa ele era fechado. Em tudo ele melhorou bastante.

E8: Ah! A gente aprende muito! Aprende muito!

Um impacto importante a ser observado é a quantidade de alunos encaminhados para as classes regulares. Estudantes que nos relatórios escolares ao ingressarem na EJA Interventiva apresentavam o quadro de não possuírem mais condições de aprendizagem, desenvolveram suas potencialidades e conseguiram prosseguir nos estudos. Segundo os relatórios de rendimento da EJA Interventiva, em 2015 dez alunos foram encaminhados para o Ensino Médio regular, três em 2016 e sete em 2017.

\section{c) A função qualificadora da EJA Interventiva}

Impactos da função qualificadora da EJA Interventiva têm possibilitado a atualização de conhecimentos com a oferta de qualificação para o mundo do trabalho a partir de cursos de formação. Propicia, portanto, condições para a inserção do estudante com deficiência no mundo do trabalho e sua participação na sociedade de forma plena como cidadãos de direito.

A EJA Interventiva, a partir destas funções, tem se apresentado como uma oportunidade concreta a jovens e adultos com deficiência intelectual e autismo e uma alternativa possível diante de suas especificidades, possibilitando o desenvolvimento da aprendizagem dos estudantes e sua qualificação.

Para efeitos de visualização, apresentamos um quadro síntese com as categorias e subcategorias que emergiram do estudo:

Quadro 1 - Categorias e Subcategorias de Análise

\begin{tabular}{|c|c|c|}
\hline \multirow{7}{*}{ 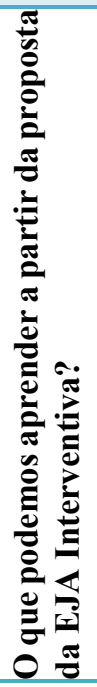 } & \multicolumn{2}{|c|}{ Categorias $\quad$ Subcategorias } \\
\hline & \multirow{2}{*}{$\begin{array}{l}\text { A EJA Interventiva - sua } \\
\text { concepção e seus } \\
\text { princípios fundantes }\end{array}$} & A trajetória do processo de concepção. \\
\hline & & A EJA Interventiva e sua organização. \\
\hline & \multirow{4}{*}{$\begin{array}{l}\text { A EJA Interventiva - } \\
\text { includente ou excludente }\end{array}$} & Possibilita o acesso à Educação e continuidade de estudos. \\
\hline & & Promove a articulação com o Ensino Regular. \\
\hline & & Desenvolve a aprendizagem do estudante. \\
\hline & & $\begin{array}{l}\text { Possibilita a profissionalização do estudante com deficiência e } \\
\text { encaminhamento para o mundo do trabalho. }\end{array}$ \\
\hline
\end{tabular}

RIAEE - Revista Ibero-Americana de Estudos em Educação, Araraquara, v. 15, n. esp. 3, p. 2446-2470, nov., 2020. E-ISSN: 1982-5587 


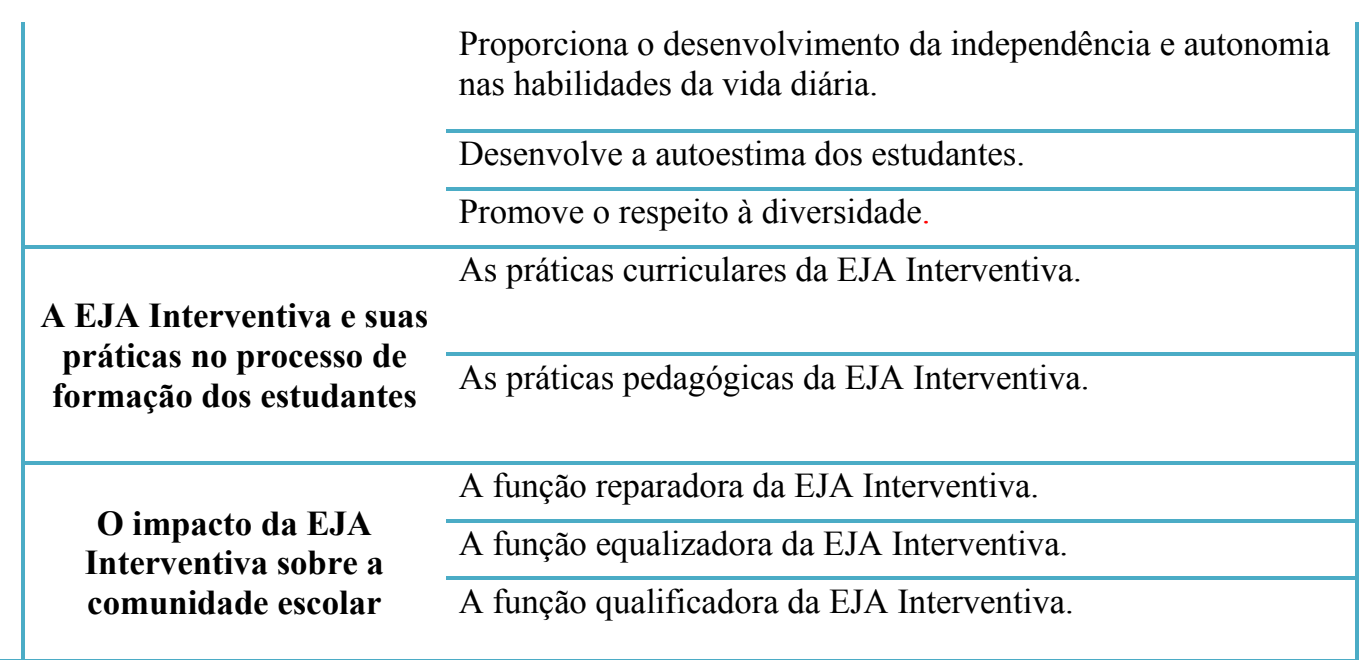

Fonte: Elaborado pelas autoras (2018)

\section{Considerações finais}

Este artigo buscou apresentar a EJA Interventiva e o processo educacional desenvolvido no Centro de Ensino Fundamental 01 de Planaltina no Distrito Federal, para que se possa conhecer e compreender o seu funcionamento e os fatores que concorrem para uma proposta de inclusão bem sucedida a estudantes com deficiência intelectual e autismo, transformando-a de projeto piloto em diretriz curricular.

Dentre os indicadores que concorrem para o sucesso da EJA Interventiva no Centrinho, destacam-se: o funcionamento em um Centro de Ensino Fundamental articulado com o Ensino Regular; ambiente específico para o acesso aos conteúdos curriculares; projetos que promovem a socialização dos estudantes da EJA Interventiva com os estudantes do Ensino Regular e toda a comunidade escolar; acesso ao currículo adaptado da EJA e ao currículo funcional; atendimento individualizado; atividades diversificadas; atendimento educacional especializado em sala de recurso; preparação para o mundo do trabalho; desenvolvimento da autoestima do estudante e a promoção do respeito à diversidade.

Os dados levantados apontam para o impacto da EJA Interventiva no que diz respeito às funções reparadora, equalizadora e qualificadora da Educação de Jovens e Adultos ao oferecer possibilidade de acesso e continuidade no processo de escolarização; práticas curriculares e pedagógicas pensadas para restabelecer a trajetória escolar dos estudantes com deficiência, favorecendo o desenvolvimento de suas aprendizagens e a qualificação e inserção no mundo do trabalho, contribuindo para a participação na sociedade como cidadãos de direito.

Apesar de se apresentar como uma alternativa de inclusão bem-sucedida, a EJA Interventiva pode avançar conforme mostraram os dados, especialmente nas adequações 
metodológicas e curriculares na direção de uma maior individualização que respeite os ritmos e necessidades dos estudantes. Essa dificuldade ajuda a compreender as limitações para atender às diversidades dos estudantes a partir da lógica curricular tradicional, com espaços e tempos padronizados para todos os alunos, apontando para a importância em se propor e implementar novos modelos curriculares.

A pesquisa possibilitou observar que projetos educacionais inclusivos bem articulados e implementados a partir do cotidiano escolar, construídos pela escola e para a escola, podem ser bem-sucedidos e orientar políticas públicas que garantam direitos básicos para a inclusão de pessoas com deficiência. A EJA Interventiva deixa o estímulo para que outras experiências alternativas possam ser construídas.

\section{REFERÊNCIAS}

ANDRÉ, M. E. D. A. Estudo de caso em pesquisa e avaliação educacional. Brasília: Liber Livro Editora, Série Pesquisa, 2005. v. 13.

BARDIN, L. Análise de conteúdo. Trad. Luís Antero Reto e Augusto Pinheiro. São Paulo: Edições 70, 2016.

BARBOSA, V. S. EJA INTERVENTIVA: de Projeto Inclusivo à Indução de Políticas Curriculares. Orientador: Elize Keller-Franco. 2018. 267 f. Dissertação (Mestrado em Educação) - Centro Universitário Adventista de São Paulo, Engenheiro Coelho, 2018.

BRASIL. Lei n. 9.394, de 20 de dezembro de 1996. Lei de Diretrizes e Bases da Educação Nacional. Diário Oficial da União: Seção 1, Brasília, DF, n. 248, p. 27833, 23 dez. 1996.

BRASIL. Política Nacional de Educação Especial na Perspectiva da Educação Inclusiva. Brasília, 2008. Disponível em: http://portal.mec.gov.br/arquivos/pdf/politicaeducespecial.pdf. Acesso em: 12 jun. 2020.

BRASÍLIA. Ministério da Educação e Cultura. Trabalhando com a Educação de Jovens e Adultos: alunas e alunos da EJA. Caderno 1. Brasília: MEC, 2006.

BRASÍLIA. Governo do Distrito Federal. Orientação Pedagógica da Educação Especial. Brasília, 2010.

BRASÍLIA. Governo do Distrito Federal. Projeto Piloto de Educação de Jovens e Adultos Interventivo $-2^{\circ}$ Segmento. Brasília, 2011.

BRASÍLIA. Governo do Distrito Federal. Currículo em Movimento da Educação Básica Educação de Jovens e Adultos. Brasília, 2014a.

BRASÍLIA. Governo do distrito Federal. Diretrizes Operacionais da Educação de Jovens e Adultos 2014/2017. Brasília, 2014b. 
BRASÍLIA. Projeto Político-Pedagógico do CEF 01 de Planaltina - Versão 2016. Brasília, 2016.

BRASÍLIA. Projeto Político-Pedagógico do CEF 01 de Planaltina - Versão 2017. Brasília, 2017.

CAMPOS, J. A. P. P.; DUARTE, M. O aluno com deficiência na EJA: reflexões sobre o atendimento educacional especializado a partir do relato de uma professora da educação especial. Revista de Educação Especial, Santa Maria, v. 24, n. 40, p. 217-284, maio/ago, 2011. Disponível em: http://www.ufsm.br/revistaeducacaoespecial. Acesso em: 12 jun. 2020.

CARVALHO, R. E. A escola inclusiva como a que remove barreiras para a aprendizagem e para a participação de todos. In: GOMES, M. (Org.) Construindo as Trilhas para a Inclusão. 2. ed. Petrópolis, RJ: Vozes, 2012.

FANTACINI, R. A. F.; CAMPOS, J. A. P. P. Conclusão da escolaridade de alunos com deficiência intelectual matriculados na Educação de Jovens e Adultos. Revista de Educação PUC-Campinas. Campinas, v. 2, n. 22, p. 317-330, maio/ago. 2017. DOI: http://doi.org/10.24220/2318-0870v22n2a3610

\section{FRIAS, E. M. A.; MENEZES, M. C. B. Inclusão Escolar do Aluno com Necessidades} Educacionais Especiais: contribuições ao professor do Ensino Regular. PDE-SEED/PR, 2009. Disponível em: http://www.diaadiaeducacao.pr.gov.br/portals/pde/arquivos/1462-8.pdf. Acesso em: 15 ago. 2020.

LAFFIN, M. H. L. F. Reciprocidade e acolhimento na educação de jovens e adultos: ações intencionais na relação com o saber. Educar em Revista, Curitiba, Editora UFPR, v. 23, n. 29, p. 101-119, 2007. DOI: http://doi.org/10.1590/S0104-40602007000100008

PACHECO, J. Berços da desigualdade. In: GOMES, M. (Org.) Construindo as Trilhas para a Inclusão. 2. ed. Petrópolis, RJ: Vozes, 2012.

PARANÁ. Inclusão e Diversidade: Reflexões para a Construção do Projeto PolíticoPedagógico. Governo do Estado do Paraná, Secretaria de Estado da Educação, Superintendência de Educação, Departamento de Educação Especial, 2010. Disponível em: www.gestaoescolar.diaadia.pr.gov.br/arquivos/File/sem_pedagogica/fev_2010/iclusao_diversi dade.pdf. Acesso em: 12 jun. 2020.

STAINBACK, S.; STAINBACK, W. Inclusão: um guia para educadores. Trad. Magda França Lopes. Porto Alegre: Artes Médicas Sul, 1999.

SEBASTIAN-HEREDERO, E.; ANACHE, A. A. A percepção docente sobre conceitos, políticas e práticas inclusivas. Estudo de caso no Brasil. Revista Ibero-Americana de Estudos em Educação, Araraquara, v. 15, n. esp. 1, p. 1018-1037, maio 2020. e-ISSN: $1982-$ 5587. DOI: https://doi.org/10.21723/riaee.v15iesp.1.13514

TRAVERSINI, C. S. Autoestima e alfabetização: o que há nessa relação? Cadernos de Pesquisa, v. 39, n. 137, maio/ago. 2009. Disponível em: http://www.scielo. br/pdf/cp/v39n137/v39n137a12.pdf. Acesso em: 12 ag. 2020. 


\section{Como referenciar este artigo}

BARBOSA, V. S.; KELLER-FRANCO, E. Projeto EJA interventiva: contribuições para as práticas e políticas curriculares inclusivas. Revista Ibero-Americana de Estudos em Educação, Araraquara, v. 15, n. esp. 3, p. 2446-2470, nov., 2020. E-ISSN: 1982-5587. DOI: https://doi.org/10.21723/riaee.v15iesp3.14451

Submetido em: 20/07/2020

Revisões requeridas em: 30/08/2020

Aprovado em: 29/09/2020

Publicado em: 30/10/2020 